\title{
EL ANÁLISIS ECONÓMICO DEL DERECHO: ALGUNAS CUESTIONES SOBRE SU JUSTIFICACIÓN
}

\section{Introducción}

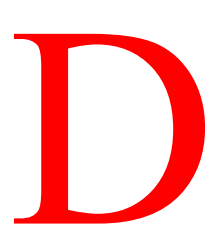

e manera cada vez más frecuente aparece en los planes de estudios de las licenciaturas en Derecho una asignatura cuyo título es «Análisis Económico del Derecho». No podemos decir que, como desde hace una década ocurre en las principales universidades estadounidenses, en los claustros de nuestras Facultades de Derecho la presencia de analistas económicos del Derecho sea notable, pero sí podemos constatar la creciente importancia que esta disciplina, o quizá mejor, que esta manera de aproximarse al fenómeno jurídico, está adquiriendo entre nuestros juristas ${ }^{1}$.

En cualquier caso, los juristas debemos asumir las importantes contribuciones que desde la economía se han realizado al análisis de las relaciones sociales e intentar tenerlas presentes cuando sea necesario -que lo es muy a menudo- en nuestros análisis del Derecho. Ello no debe impedirnos ser conscientes de algunos de los peligros implícitos en esa política expansionista de los economistas, o para no personalizar, del análisis económico. Importantes contribuciones de la ciencia económica -estoy pensando en este momento en el Teorema de Coase- pueden haber sido empujadas más allá de sus límites razonables hasta convertirlas en punto de partida del discurso moral; lo cual no parece aceptable ${ }^{2}$. Asimismo, la relevancia casi

${ }^{1}$ Un exponente de la gran relevancia a nivel internacional de este tipo de análisis lo encontramos en la abundante bibliografía que se ha producido en los últimos años. Véase Bouckaert, B. y De Geest, G., Bibliography of Law and Economics, Kluwer Academic Publishers, Dordrecht, 1992.

${ }^{2}$ En este sentido, Charles Fried, «Difficulties in the economic analysis of rights», en Markets and Morals, Dworkin, G., Bermant, G. y Brown P. G. (eds.), Hemisphere Publishing Corporation, Washington, 1977, págs. 175 y ss. 
exclusiva dada por el análisis económico al problema de la eficiencia, no sólo deja sin resolver cuál es el concepto más correcto de eficiencia (Pareto, Kaldor-Hicks, maximización de la riqueza... $)^{3}$, sino que soslaya el posible conflicto con otros criterios normativos (justicia, igualdad...), y además olvida otras importantes cuestiones éticas, principalmente las conectadas con la asunción de que todos los bienes son económicos; como ha señalado Elizabeth Anderson ${ }^{4}$, «tendríamos que preocuparnos también por el tipo de personas y de comunidades que estamos construyendo cuando consideramos a las mujeres como factorías comerciales de bebés, a los espacios públicos de interacción social como lugares para comerciar o a evitar, y el medio ambiente como cualquier otro recurso económico a explotar».

\section{2. ¿Qué es el análisis económico del Derecho?}

Ciertamente bajo este título se engloban diferentes aproximaciones al fenómeno jurídico, unas de carácter descriptivo y otras de carácter normativo. Antes de entrar a analizar con precisión el significado del análisis económico del Derecho, quiero realizar unas puntualizaciones previas acerca de la necesidad de superar, desde el análisis económico, algunas de las insuficiencias tradicionales de la ciencia jurídica dominante en la cultura continental durante los dos últimos siglos.

\subsection{Dogmática Jurídica, Política jurídica y análisis económico}

Quizá la insuficiencia fundamental de la Dogmática jurídica haya consistido en su incapacidad para plantear cuestiones cruciales que pueden servir de guía al legislador; con otras palabras, en su radical separación de la política jurídica. En efecto, la Dogmática Jurídica ha consistido en una actividad reflexiva sobre un objeto dado, el Derecho positivo; se trata de una actividad lógico-formal o deductiva preocupada por organizar lógica y sistemáticamente un determinado material -las normas jurídicas- de cara a facilitar su aplicación.

\footnotetext{
${ }^{3}$ En este sentido, Jules Coleman ha señalado lo siguiente: «Mi sugerencia es que una gran cantidad de confusión existente en la literatura se debe a la incapacidad de apreciar lo diferentes que varias teorías económicas (todos descansando en la deseabilidad de promover la eficiencia) pueden llegar a ser». en «The foundations of constitutional economics», en Markets, Morals and the Law, Cambridge University Press, 1988, pág. 144.
}

${ }^{4}$ Value in Ethics and Economics, Harvard University Press, 1993, prefacio, pág. XI. 
Puede, en este sentido, decirse que los problemas más relevantes que se han planteado los juristas dogmáticos son de carácter intrasistemático; analizaban -y analizansi en el interior de los sistemas jurídicos existen normas incompatibles o ambiguas, o lagunas o conceptos jurídicos indeterminados, en definitiva, su actividad descansa en un determinado concepto de racionalidad, la denominada racionalidad jurídico-formal.

Precisamente por ello, y tal y como apuntaba anteriormente, la Dogmática jurídica se ha manifestado incapaz de ofrecer pautas de actuación -salvo los citados requisitos lógico-formales- para los agentes sociales encargados de legislar. Y por ello resulta plenamente justificada la crítica que apunta a los juristas (dogmáticos) como seres poco sensibles al análisis de los problemas jurídicos desde el punto de vista de su justicia o injusticia, de sus consecuencias sociales o de sus costes y su eficiencia.

Proclamar hoy la necesidad de tomar en consideración las previsibles consecuencias sociales de una norma antes de su elaboración, o de analizar su justicia o injusticia, es un asunto pacífico. Sin embargo, proclamar la necesidad de analizar la eficiencia o ineficiencia de dicha norma puede originar alguna controversia. Probablemente el origen de la misma se encuentre en una idea que se encuentra muy generalizada y que George Stigler $^{5}$ ha sabido resumir:

«La diferencia entre una disciplina que persigue explicar la vida económica (y también todo comportamiento racional) y una disciplina que persigue alcanzar la justicia regulando todos los aspectos del comportamiento humano es profunda. Esta diferencia significa que, básicamente, el economista y el jurista viven en diferentes mundos y hablan diferentes lenguajes».

Aun asumiendo los diferentes objetivos de ambas disciplinas, ¿podemos seguir aceptando pacíficamente que juristas y economistas sigan viviendo en dos mundos diferentes y hablando dos lenguajes mutuamente ininteligibles? ¿No podrán ofrecer los economistas algunas herramientas útiles de cara a conseguir el objetivo de los juristas, a saber, alcanzar la justicia regulando todos los aspectos del comportamiento humano? ¿No estarán, por su parte, los juristas en condiciones de ofrecer a los economistas, en su intento de explicar la vida económica y en general todo comportamiento racional, algunas claves acerca de la existencia de algunos bienes valiosos, difíciles de

\footnotetext{
${ }^{5}$ «Law or Economics?», en Journal of Law and Economics, vol. XXXV, oct. 1992, págs. 455-468.
} 
valorar desde los presupuestos del análisis económico? Creo que la primera respuesta negativa, debe ir acompañada de dos respuestas afirmativas.

Centrándonos ahora en aquellas aportaciones del análisis económico que pueden resultarnos de utilidad en nuestro intento de superar las deficiencias de la Dogmática jurídica antes apuntadas, podemos sugerir las siguientes:

(i) Es sabido que el análisis económico concibe al individuo como hombre económico, es decir, como agente racional maximizador de su bienestar, en un contexto caracterizado por la escasez de recursos. Creo que sería un error -aunque no es éste el lugar para argumentarlo- reducir el hombre jurídico al hombre económico ${ }^{6}$, pero esa salvedad no debe ser óbice para que reconozcamos que, en muchas ocasiones, los individuos en relación con el Derecho se comportan como agentes racionales maximizadores de su bienestar; lo cual va a querer decir que el comportamiento jurídicamente relevante de los individuos en ocasiones vendrá determinado no tanto por razones morales, como por razones prudenciales; asimismo, implicará que los individuos responden a incentivos, es decir, que si su entorno cambia de tal modo que pueden mejorar su nivel de bienestar modificando sus pautas de conducta, éstos lo harán. En tanto en cuanto las normas jurídicas supongan variaciones del entorno, los individuos variarán su comportamiento, obedeciendo o desobedeciendo las normas, en función de lo que requiera la maximización de su bienestar.

(ii) Desde esta perspectiva, Albert Calsamiglia ${ }^{7}$ ha propuesto retomar una distinción formulada desde el análisis económico entre racionalidad paramétrica y racionalidad estratégica ${ }^{8}$ para analizar

${ }^{6}$ Posner, sin embargo, se manifiesta a favor de la aplicabilidad a todas las esferas de la vida humana del supuesto de los individuos como agentes racionales maximizadores de su bienestar. Sus palabras son elocuentes: «Considero contraintuitiva e implausible una concepción rígidamente compartamentalizada de los procesos de toma de decisión de los individuos, de tal manera que éstos actuarán racionalmente a la hora de hacer una adquisición trivial y lo harán irracionalmente a la hora de decidir si estudiarán o no Derecho, si se casarán, evadirán impuestos, o tendrán tres hijos mejor que dos...», The Economics of Justice, Harvard University Press, 1983, pág. 2.

${ }^{7}$ «Justicia, eficiencia y optimización de la legislación», en Documentación Administrativa, $\mathrm{n}^{\mathrm{o}}$. 218-219, abril-septiembre 1989, págs. 113-151.

${ }^{8}$ Mientras que la racionalidad paramétrica opera en aquellas situaciones en las que las preferencias de un individuo son las únicas variables, no tomándose en cuenta las preferencias de los demás, la racionalidad estratégica opera cuando las elecciones de los agentes están determinadas por las elecciones de otros sujetos, y por ello a la hora de tomar una decisión hay que considerar las elecciones de los demás y la conducta esperada de ellos. 
el comportamiento de los individuos ante el Derecho. Su idea es que la noción de racionalidad estratégica es relevante para la toma de decisiones sociales y que muchas situaciones jurídicas no suponen racionalidades paramétricas, sino estratégicas, en el sentido de que los individuos reaccionan ante las leyes, y por eso hay que prever cuál va a ser la reacción de éstos a la hora de elaborar la ley. En definitiva, en muchas ocasiones -pero no siempre, ni todos- los destinatarios de las normas reaccionan estratégicamente frente a ellas; toman las normas como un dato, y no como la conducta a seguir obligatoriamente; como ya hemos apuntado, las normas crean incentivos, y si no están bien formuladas, puede ocurrir que esos incentivos lo sean a su incumplimiento.

(iii) Los economistas suelen poner mucho énfasis en que las normas jurídicas sean eficientes. Qué es lo que con ello quieren decir es cuestión controvertida. Asumamos de momento que tan sólo significa que deben contribuir a alcanzar los objetivos socialmente deseados de la manera menos costosa9. En este sentido no parece descartable que las normas deban ser eficientes, entre otras razones porque, dada la escasez de recursos existentes, derrocharlos parecería injusto.

Manuel Atienza, en sus trabajos sobre Ciencia de la Legislación ${ }^{10}$, a la hora de determinar cuáles son los requisitos que deben satisfacer las buenas leyes, ha apuntado que éstas deben satisfacer cinco racionalidades: comunicativa, jurídico-formal, ética, pragmática y teleológica. Voy a detenerme en las dos últimas, pues son las que tienen alguna conexión con los problemas que aquí estamos abordando. Por racionalidad pragmática Atienza entiende que las normas deben ser formuladas de tal modo que logren que las conductas de los individuos se ajusten a lo prescrito en la ley, o lo que es lo mismo, que sean eficaces; si asumimos con Calsamiglia, que muchas situaciones jurídicas son estratégicas, y que las normas modifican el entorno de incentivos de los individuos, elaborar normas eficaces no es una tarea trivial.

Cuando Atienza señala que las normas jurídicas deben satisfacer las exigencias de racionalidad teleológica, está apuntando que, en la medida en que las normas son instrumentos para conseguir determinados objetivos sociales, deben contribuir a alcanzarlos, deben ser

${ }^{9}$ Éste es el concepto de eficiencia que propone Stigler al tiempo que critica el de Posner, en «Law or Economics», citado, concretamente en el apartado II, «Efficient Law».

${ }^{10}$ Véase «Sociología jurídica y ciencia de la legislación», en Bergalli, R. (coordinador), El Derecho y sus realidades. Investigación y enseñanza de la sociología jurídica, PPU, Barcelona, 1989, y «Contribución para una teoría de la legislación», en Doxa, nº. 6, 1989, págs. 385-403. 
eficientes. Calsamiglia ${ }^{11}$, por su parte, subdivide este requisito de eficiencia social en dos: por un lado, dirá, las normas deben ser efectivas (es decir, deben ayudar a alcanzar los fines que persiguen) y por otro, deben ser eficientes (deben alcanzar tales fines con los medios e instrumentos más adecuados y menos costosos).

Debe quedar claro que este concepto de eficiencia que estamos asumiendo presupone dos elementos valiosos con los que alcanzar tal objetivo; en este sentido, la eficiencia consiste en alcanzar un máximo valor de output -en nuestro caso el objetivo socialmente deseado- con un valor dado de inputs.

El análisis económico, sin lugar a dudas, puede ofrecer instrumental de gran utilidad de cara a alcanzar ese objetivo de elaborar leyes racionales no sólo desde un punto de vista comunicativo, jurídico-formal y ético, sino también con palabras de Atienza, pragmático y teleológico. La política jurídica requiere de una pluralidad de saberes, y entre ellos el económico ciertamente ocupa un lugar destacado.

\subsection{El análisis económico del Derecho}

Bajo este título no hay que englobar cualquier tipo de aproximación económica al fenómeno jurídico, ni cualquier tipo de reivindicación de la importancia del análisis económico de cara a una cabal comprensión del Derecho. Probablemente tampoco sea correcto concebir el análisis económico del Derecho como una determinada escuela o corriente filosófico-jurídica, pues realmente no presenta una gran homogeneidad.

Siguiendo a Posner ${ }^{12}$, podemos distinguir dos ramas dentro del análisis económico del Derecho: por un lado, la clásica, el análisis de las normas reguladores de la actividad explícitamente económica (lees antitrust, sistema impositivo, comercio internacional...), que se remontaría a los análisis de Adam Smith sobre las consecuencias económicas de la legislación mercantilista; por otro lado, una rama más reciente, que encuentra su origen en dos trabajos de Ronald Coase ${ }^{13}$ y Guido Calabresi ${ }^{14}$, y que se caracteriza, por un lado, por extender el

${ }^{11}$ «Justicia, eficiencia...» citada, págs. 143-145.

${ }^{12}$ The Economics of Justice, citada, págs. 3-5.

13 «The Problem of Social Cost» en Journal of Law and Economics, 3, 1960. (Hay traducción española «El problema del coste social», en Hacienda Pública Española, n. ${ }^{\circ}$ 68, 1981, págs. 245-374).

${ }^{14}$ «Some Thoughts on Risk Distribution and the Law of Torts», Yale LawmJournal, 70, 1961, págs. 449 y ss. 
análisis económico a sectores del ordenamiento jurídico que no regulan actividades económicas -sectores ajenos al mercado-, y por otro lado, por proponer un doble objetivo para el Derecho: proveer las condiciones necesarias para que el mercado funcione e imitar al mercado cuando su libre desenvolvimiento no sea factible.

Cabe, sin embargo, una mayor precisión a la hora de concretar las diferentes actividades que caen dentro del análisis económico del Derecho. Jules Coleman ${ }^{15}$ ha propuesto diferenciar tres tipos de actividades, dos de carácter analítico (una descriptiva y otra positiva) y una de naturaleza normativa. Por mi parte, creo que es posible distinguir dos tipos de análisis normativo sustancialmente diferentes. Veamos la propuesta de Coleman:

(a) Descriptiva: se basa en el principio de eficiencia económica como herramienta explicativa de reglas legales y decisiones judiciales. El artículo de Posner «Theory of Negligence ${ }^{16}{ }^{6}$, señala Coleman, es un buen ejemplo de este planteamiento; en él, Posner muestra cómo la resolución de un buen número de casos de negligencia puede ser entendida a la luz del principio de eficiencia. Posner sostiene, genéricamente, que muchos sectores del ordenamiento, especial pero no únicamente, las grandes áreas del common law (propiedad, accidentes, delitos y contratos), deben ser comprendidos como un sistema que persigue la eficiencia, o lo que es lo mismo, maximizar la riqueza de la sociedad ${ }^{17}$. Admite, sin embargo, que el criterio de eficiencia no explica importantes reglas constitucionales, como las relativas a la no discriminación racial, ni importantes decisiones de la Corte Suprema, como las relativas a la doctrina constitucional en materia de intimidad ${ }^{18}$.

(b) Positiva: proclama la capacidad de los «modelos de mercado» para proporcionar un aparato conceptual en el que los problemas legales puedan ser analizados ${ }^{19}$.

(c) Normativa: normas jurídicas existentes son evaluadas y nuevas

${ }^{15}$ «Efficiency, Auction and Exchange», en Markets, Morals and the Law, citada, págs. 67-68.

${ }^{16}$ Journal of Legal Studies, I, 1972, págs. 29 y ss.

${ }^{17}$ Economic Analysis of law, 3 a . ed. Little Brown and Co., 1986, pág. 20-22. Véase sobre todo el capítulo 8, «The Common Law, Legal History and Jurisprudence». Una defensa del carácter eficiente y no utilitarista del common law en «The ethical and political basis of wealth maximization», en The Economics of Justice, citada, págs. 103-107.

${ }^{18}$ Véase The Economics of Justice, capítulo 11, «The Privacy Jurisprudence of the Supreme Court», y el apartado IV, «The Supreme Court and Discrimination».

${ }^{19} \mathrm{El}$ ejemplo de este tipo de análisis que propone Coleman es un trabajo en materia penal de Isaac Ehrlich, «The Deterrent Effects of Criminal Law Enforcement», Journal of Legal Studies, 1, 1972, págs. 259 y ss. 
normas son propuestas en función de su eficiencia económica ${ }^{20}$.

Apuntaba anteriormente que el análisis económico del Derecho de tipo normativo es susceptible de ser dividido en dos actividades diferentes; por plantearlo en términos de autores: aun siendo análisis normativo -y por tanto un análisis que evalúa y realiza propuestas sobre la base de criterios de eficiencia- tanto el realizado por Posner como el propuesto por Calabresi, cabe establecer sustanciales diferencias entre ambos, y sobre todo entre dos maneras diferentes de entender el papel del principio de eficiencia. No es lo mismo afirmar, como lo hace Calabresi ${ }^{21}$, que el objetivo de un determinado sector del ordenamiento jurídico -por ejemplo el Derecho de accidentes- es doble, perseguir la justicia y reducir los costes, que proclamar, como lo hace Posner, que «la eficiencia, tal y como yo concibo el término, es un adecuado concepto de justicia» ${ }^{22}$.

En efecto, Calabresi se limita a reivindicar el importante papel que el criterio de eficiencia debe jugar en amplios campos del ordenamiento, pero es consciente de las limitaciones del mismo y de su escasa relevancia moral ${ }^{23}$, e incluso, cuando Dworkin le acusa de postular un cierto compromiso o trade-off entre justicia y eficiencia ${ }^{24}$, señala que el principio de justicia debe ejercer un papel de veto ante las exigencias de la eficiencia ${ }^{25}$.

${ }^{20} \mathrm{El}$ ejemplo que propone Coleman es el libro de Guido Calabresi The Cost of Accidents: A Legal and Economic Analysis, Yale University Press, 1970 (traducción española El cosle de los accidentes. Análisis económico y jurídico de la responsabilidad civil, Ariel, Barcelona, 1984).

${ }^{21}$ Por ejemplo en El coste de los accidentes..., citada.

${ }^{22}$ The Economics of Justice, citada, pág. 6. Podemos adelantar que el concepto de eficiencia que propone Posner es sinónimo de «maximización de la riqueza» («wealth maximization»).

${ }^{23}$ Véase, por ejemplo, «Sobre los límites de los análisis no económicos del Derecho», en Anuario de Filosofía del Derecho, 1985, págs. 221-228, o su artículo con A. D. Melamed, «Property rules, liability rules and inalienability: one view of the cathedral», en Harvard Law Review, vol. 85, $\mathrm{n}^{\circ} .6$, 1972, págs. 1089-1128.

${ }^{24}$ Véase «Is wealth a value?», en $A$ matter of principle, Clarendon Press, Oxford, 1986, págs. 237-266 (inicialmente publicado en Journal of Legal Studies, 9, 1980). Dworkin sostiene que Calabresi (El coste social..., citada) admite que los dos grandes objetivos que el Derecho de accidentes debe perseguir, la justicia y reducir los costes, pueden entrar en conflicto, siendo necesario en esos casos adoptar una decisión política acerca del objetivo a perseguir, siendo posible un cierto compromiso o trade-off entre justicia y eficiencia. En opinión de Dworkin, el planteamiento de Calabresi es representativo de la teoría, agudamente criticada por Dworkin, que defiende que la riqueza social es uno de entre los varios componentes del valor social. Esta teoría quedaría perfectamente ilustrada con las célebres curvas de indiferencia dibujadas en espacios definidos por dos ejes, uno de los cuales sería la justicia (o moralidad) y el otro, la riqueza social (o eficiencia). La conclusión de Dworkin es que «es absurdo considerar la maximización de la riqueza como un componente del valor...» (pág. 248).

${ }^{25}$ «About Law and Economics: A letter to Ronald Dworkin», Hofstra Law 
La propuesta de Posner, como sugería anteriormente, es mucho más ambiciosa; formula una teoría normativa del Derecho, alternativa tanto a las teorías utilitaristas como a las de origen kantiano. Merece ser analizada con más detenimiento.

\subsection{La eficiencia como justicia. Richard Posner}

Los títulos de las dos obras fundamentales de Posner, Economic Analysis of Law y The Economics of Justice reflejan perfectamente el objetivo de sus trabajos, demostrar la capacidad del análisis económico para explicar y ordenar áreas del comportamiento social que no suelen ser concebidas como económicas. No es, en este sentido, exagerado afirmar que Posner no sólo se ha aventurado a proponer una Teoría económica del Derecho, sino también una Teoría Económica de la Justicia, que establezca los contenidos que el Derecho debe respetar, y que señale las pautas que los jueces deben seguir en la aplicación del Derecho $^{26}$. El objetivo que proclama ${ }^{27}$ es que «la ética que está implícita en la teoría del valor o del precio -la ética que yo he llamado de la «maximización de la riqueza»- sea analizada junto a otras éticas». Es consciente, sin embargo, de que una aplicación estricta de la misma produciría resultados inaceptables ${ }^{28}$, y por eso, quizá, señala que sus propuestas éticas deben ser consideradas más como materia de especulación que como un conjunto de fórmulas para la acción social ${ }^{29}$.

En todo caso, Posner quiere sentar las bases de una teoría ética alternativa tanto al utilitarismo como a las éticas kantianas. Parte de la necesidad de diferenciar el utilitarismo de los principios éticos

Review, 8, 1980, págs. 553 y ss. Es su respuesta al artículo de Dworkin, «Is wealth a value?». Éste a su vez le responderá en «Why efficiency», en A matter of principle, citada, págs. 267-289.

${ }^{26}$ Una crítica del papel que Posner atribuye a los jueces, en Dworkin, «Why efficiency?», citada, págs. 275 y ss., y en Coleman, «Efficiency. Utility and Wealth Maximization», en Markets, Morals..., citada, págs. 130-132.

${ }^{27}$ The Economics of Justice..., citada, prefacio a la $2^{\mathrm{a}}$. ed. pág. V.

${ }^{28}$ Asume que en caso de que la hormona del crecimiento fuera muy escasa, su teoría conduciría a asignarla antes a un galán rico que quisiera crecer un poco más que a un enano pobre incapaz de pagar por dicha hormona. De todos modos, Posner no es un autor que se caracterice por su sensibilidad moral. Un ejemplo ilustrativo es una observación que realiza a alguna de las críticas que le dirigió Dworkin en «Is wealth a value?», citada. Posner argumenta del siguiente modo: «Dworkin establece que 'una teoría que hace depender el valor moral de la esclavitud de los costes de transacción es grotesca'. No lo argumenta». Véase «The ethical and political basis of wealth maximization», citada, pág. 111 , nota 47.

${ }^{29}$ Ibídem. 
subyacentes en el análisis económico, para posteriormente criticar las concepciones utilitaristas, fundamentalmente por la imposibilidad de comparar y agregar utilidades de gentes diferentes ${ }^{30}$. Propone la idea de «maximizacion de la riqueza» como alternativa a la idea utilitarista de maximizar la utilidad, creyendo que de ese modo se pueden eludir las deficiencias del utilitarismo. Cuando Posner habla de riqueza está haciendo referencia a la suma de todos los bienes y servicios existentes en la sociedad medidos por su valor, y aunque dice expresamente que valor no es lo mismo que precio (y nos recuerda la noción de excedente del consumidor y del productor), su concepción de la «maximización de la riqueza» puede plantear algunas dudas:

«La idea más importante que tenemos que tener presente en relación al concepto de valor es que está basado en lo que la gente está deseando pagar por algo, más que en la felicidad que derivarán de su tenencia... Pero mientras el valor necesariamente implica utilidad, la utilidad no implica necesariamente valor. El individuo que desearía enormemente tener un bien pero no quiere o es incapaz de pagar por él -quizá porque es indigente- no valora el bien en el sentido en el que yo estoy usando el término 'valor'» $)^{31}$.

En todo caso, como decía, propone como objetivo ético último del sistema social maximizar la riqueza, objetivo que sitúa en estrecha relación con el de respetar el funcionamiento de los mercados y con el de imitarlos cuando el libre funcionamiento de los mismos no sea posible. Posner asume las críticas dirigidas al utilitarismo por justificar invasiones a la libertad individual y por sacrificar a individuos inocentes en el altar de la necesidad social; pero cree que una insistencia excesiva en la libertad o autonomía individuales, con

\footnotetext{
${ }^{30}$ «Blackstone y Bentham», en The Economics..., págs. 13-47.

${ }^{31}$ «Utilitarianism, Economics, and Social Theory», en The Economics..., citada, pág. 60. Y añade que «la riqueza de la sociedad está constituida por la satisfacción agregada de aquellas preferencias (las únicas que tienen peso ético en un sistema de maximización de la riqueza) que están respaldadas por dinero, es decir, que están registradas en un mercado» (pág. 61 ); sin embargo, ese mercado no tendrá por qué ser explícito y por ello «la riqueza no es equivalente al Producto Nacional Bruto ni a ninguna otra medida pecuniaria del bienestar» (pág. 61 ). Coleman sostiene que Posner hace descansar la noción de maximización de la riqueza en los precios y lo critica («Efficiency, Utility and...», citada, págs. 108-111). Russell Hardin, un defensor de los planteamientos posnerianos, por el contrario, rechaza que el criterio de maximización de la riqueza no sea sino el criterio de eficiencia de Kaldor-Hicks medido a precios de mercado. Véase «The morality of Law and Economics», en Law and Philosophy, 11, 1992, pág. 345.
} 
independencia de sus consecuencias para la felicidad o utilidad del conjunto de la sociedad, es igualmente inaceptable ${ }^{32}$. Por eso, persigue distanciarse tanto de la «monstruosidad moral» del utilitarismo como del «fanatismo moral» kantiano, y propone una teoría ética alternativa a ambas, o mejor, combinación de ambas. Con sus propias palabras:

«La ética de la maximización de la riqueza puede ser entendida como una mezcla de estas dos tradiciones filosóficas rivales. La riqueza está positivamente correlacionada, aunque de manera imperfecta, con la utilidad; pero la persecución de la riqueza, al descansar en el modelo de las transacciones voluntarias del mercado, implica un mayor respeto a la libre elección individual que el utilitarismo clásico» ${ }^{33}$.

A una conclusión semejante llega cuando da un repaso a los diferentes conceptos de eficiencia para defender el criterio de Kaldor- Hicks ${ }^{34}$; en su opinión, esta es la manera de conciliar la exigencia de maximizar la riqueza con el respeto a la autonomía individual que reclaman las teorías morales consensualistas ${ }^{35}$.

Posner encuentra cinco grandes ventajas en su propuesta ${ }^{36}$ :

(a) Explica satisfactoriamente el porqué de la crítica moral a los delitos contra la propiedad.

(b) Fundamenta más sólidamente que el utilitarismo la libertad económica.

(c) Fundamenta la mayoría de las virtudes convencionales: mantenimiento de las promesas, decir la verdad, e incluso el altruismo.

(d) Proporciona una sólida justificación a una teoría distributiva de la justicia.

(e) Ofrece un aceptable concepto de Derecho.

${ }^{32} \ll \ldots$ la ética de la autonomía personal, interpretada y aplicada sin tener en consideración sus consecuencias en térnimos de bienestar, (...) produciría una gran cantidad de miseria». «The ethical and political basis of wealth maximization», en The Economics..., citada, pág. 98.

${ }^{33}$ The Economics..., citada, pág. 66.

${ }^{34}$ «The ethical and political...», citada, fundamentalmente el primer epígrafe, «The consensual basis of efficiency», págs. 88-102.

${ }^{35}$ «La maximización de la riqueza como principio ético toma en consideración tanto la utilidad, aunque menos intensamente que el utilitarismo, como el consentimiento, aunque también menos intensamente de lo que Kant lo hubiera hecho». «The ethical and political...», citada, pág. 98. La noción posneriana de consentimiento ha sido criticada por Dworkin («Why efficiency?», citada, págs. 275 y ss.) y Coleman («Efficiency, utility...», citada, págs. 115 y ss.).

${ }^{36} \ll$ Utilitarianism, Economics...», citada, págs. 66-75. 
Un planteamiento como el de Posner ha sido objeto de importantes controversias, siendo Ronald Dworkin ${ }^{37}$ y Jules Coleman ${ }^{38}$ dos de sus más feroces críticos.

\section{Algunas cuestiones básicas}

No querría concluir esta visión panorámica sobre el análisis económico del Derecho sin llamar de nuevo la atención sobre la necesidad de plantearnos la corrección de los supuestos en los que descansa y de los objetivos que persigue. Jules Coleman ${ }^{39}$ ha señalado cuatro cuestiones fundamentales que los analistas económicos del Derecho deben responder:

(i) ¿Qué es la eficiencia económica?; ¿qué significa proclamar que los recursos son asignados de un modo económicamente eficiente?; ¿qué significa proclamar que un cuerpo legal es eficiente? No descubrimos nada si apuntamos que estas preguntas no tienen una única respuesta ${ }^{40}$.

(ii) ¿Tiene el principio de eficiencia alguna virtud explicativa?; pueden un conjunto de reglas y principios jurídicos ser racionalizados y explicados por una teoría económica de la legislación o de la adjudicación? ${ }^{41}$

(iii) ¿Cómo debe ser formulado el Derecho para promover la eficiencia?; ¿cómo deben ser asignados y protegidos los deberes y derechos legales de modo que las normas que los asignan y protegen sean eficientes? ${ }^{42}$

\footnotetext{
${ }^{37}$ Véase «Is wealth a value?» y «Why efficiency?», citadas. Un riguroso análisis de las controversias entre Dworkin y Posner en Liborio Hierro, «Dworkin vs. Posner. Contra el imperio de la riqueza», en Ronald Dworkin. Estudios en su homenaje, Revista de Ciencias Sociales, no. 38, Valparaíso, 1993, págs. 383-411.

${ }^{38}$ Fundamentalmente en «Efficiency. Auction and Exchange» $\mathrm{y}$ «Efficiency, Utility and Wealth Maximization», citadas.

${ }^{39}$ «Efficiency, utility...», citada, pág. 95.

${ }^{40}$ Un buen análisis de los distintos conceptos de eficiencia en Coleman, «Efficiency, Auction and Exchange», citada.

${ }^{41}$ Una contundente respuesta negativa, y por tanto una abierta crítica a los planteamientos de Posner, en Owen Fiss, «¿La muerte del Derecho?», en Doxa, no . 10, 1991, págs. 123 y ss. También Dworkin critica la dimensión descriptiva del análisis económico del Derecho en «Is wealth a value?», citada, págs. 263-266.

${ }^{42}$ Quizá uno de los temas más controvertidos del análisis económico del Derecho sea, precisamente, el concepto de derecho subjetivo que proponen, y que como ha criticado Charles Fried, «resulta contraintuitivo, en la medida en que sugiere que todos los derechos, incluso derechos básicos como la libertad de conciencia, derechos políticos, o el derecho a no ser sometido a malos tratos, no son derechos morales sino derivaciones contingentes de un mecanismo optimizador». («Difficulties in the Economic Analysis of Rights», citada, pág. 181). Sobre el análi-
} 
(iv) ¿Debe el Derecho perseguir la eficiencia económica?; ¿en qué medida es la eficiencia un valor jurídico deseable y un principio normativo atractivo?; incluso, tal y como se preguntaba Dworkin ${ }^{43}$, ¿es la eficiencia -la entendamos como la entendamos- valiosa en sí misma, en tanto que componente (único o uno junto a otros) del valor social, o lo es en la medida en que contribuya a alcanzar fines valiosos en sí mismos, es decir en tanto que instrumento del valor social?

Las cuestiones básicas que el analista económico del Derecho debe responder no se agotan en las cuatro anteriores. Dicho análisis descansa en una serie de supuestos que conviene explicitar y cuestionarse:

(a) ¿Es razonable hacer descansar el análisis -descriptivo y normativo- del Derecho en el supuesto de que los individuos son siempre agentes racionales maximizadores de su bienestar? ¿No obviamos importantes dimensiones del ser humano? ¿No oscurecemos de ese modo el papel del diálogo y de la relación con otros en la adopción de la conciencia de nosotros mismos? ¿Cabe seguir asumiendo acríticamente el supuesto de la soberanía del consumidor, rechazando radicalmente cualquier política paternalista?

(b) ¿Son todos los bienes «bienes económicos»? Elizabeth Anderson ${ }^{44}$ ha definido los bienes económicos en función de dos características: en primer lugar, su valor puede ser plenamente realizado con el uso, siendo el uso un modo de valoración bajo e impersonal que consiste en subordinar el bien en cuestión a los fines del sujeto sin considerar su valor intrínseco; en segundo lugar, su producción, distribución y disfrute están gobernados por las reglas constitutivas del mercado ${ }^{45}$. Podemos preguntarnos también: ¿son

sis económico de los derechos, la propuesta más ortodoxa es la de Posner, Economic Analysis of law, citada, concretamente la parte II, «The common law», y también en «Utilitarianism, Economics and social theory», citada, págs. 69-74; un planteamiento diferente en Calabresi y Melamed, «Property rules, liability rules and inalienability: one view of the cathedral», citada. Un análisis crítico con la propuesta de Calabresi y Melamed en Coleman, «Rethinking the theory of legal rights», en Markets, morals..., citada, págs. 28-63.

${ }^{43}$ «Is wealth a value?», citada.

${ }^{44}$ Value in Ethics..., citada, capítulo 7, «The ethical limitations of the market», págs. 141-167, concretamente, págs. 143-146.

${ }^{45}$ Estas reglas se caracterizan por cinco rasgos: impersonalidad (es la renta y no el status social, las características personales, o las relaciones sociales, la que determina el acceso a los bienes); egoísmo (las partes en el mercado persiguen la satisfacción de sus objetivos, definidos con absoluta independencia de los objetivos de la otra parte); exclusividad (el acceso a los beneficios está limitado al propietario); «want-regarding» (los bienes se intercambian sin tener en consideración las 
todos los bienes intercambiables con la misma moneda? ${ }^{46}{ }$ Es el sistema de precios universal ${ }^{47}$ ¿Existen bienes inconmensurables? ${ }^{48}$

(c) ¿Puede discutirse racionalmente de valores morales?, o ¿deben ser éstos absolutamente relativizados?; ¿son los valores equiparables a las preferencias individuales ${ }^{49}$, no pudiendo, por tanto, establecerse ninguna jerarquía entre ellos, gozando todos de igual título a ser satisfechos? ¿Puede aceptarse pacíficamente que el valor de un bien viene dado por la cantidad que estamos dispuestos a pagar por él (o a recibir a cambio de desprendernos de él, aunque ambas cantidades no sean coincidentes)? ¿No tiene sentido distinguir, como, basándose en Kant, ha sugerido recientemente Anderson, ${ }^{50}$ entre

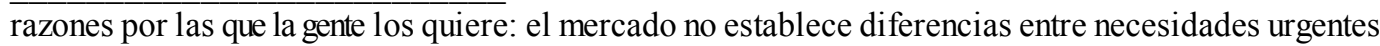
y meros caprichos); «exit not voice» (los bienes en el mercado se toman o se dejan).

${ }^{46}$ Calabresi señala que ésta es precisamente una crítica acertada dirigida al análisis económico del Derecho desde lo que él llama el «método filosófico», cuyos más ilustres representantes serían Bruce Ackerman y Ronald Dworkin. Las palabras de Calabresi son esclarecedoras: «Sin embargo hemos de admitir que el método filosófico contiene una crítica acertada al análisis económico del Derecho cuando señala que este último tiende a tratar las cosas como si todas fuesen intercambiables con la misma moneda, ignorando que el intercambio de derechos, de bienes jurídicos es muy complejo, ignorando que muchas veces hay que convertir dólares en pesetas o realizar el intercambio en el mercado negro», en «Sobre los límites de los análisis no económicos del Derecho», citada, pág. 225.

${ }^{47}$ Kenneth J. Arrow, comentando críticamente un libro muy controvertido en la década de los 70 (Richard Titmuss, The Gift Relationship: From Human Blood to Social Policy, Allen and Unwin, Londres, 1970), señalaba que «el sistema de precios no es, y quizas en algún sentido básico no puede ser, universal. En la medida en que es incompleto, debe ser completado con un implícito o explícito contrato social» (que explicara los deseos «altruistas» de los individuos). Véase "Gifts and exchanges», en Edmund S. Phelps ed., Altruism, Morality and Economic Theory, Russell Sage Foundation, Nueva York, 1975, págs. 13-28.

${ }^{48}$ Sobre el problema de la inconmensurabilidad, véase, J. Raz, The morality of freedom, Clarendon Press, Oxford, 1986, concretamente el capítulo 13, «Incommensurability», págs. 321-366, y E. Anderson, Value in Ethics and Economics, citada, capítulo 3, «Pluralism and incommensurable goods», págs. 44-64.

${ }^{49}$ Una crítica del concepto de valor en el que descansa la economía, en Griffin, «Contra el modelo del gusto», en Doxa, $\mathrm{n}^{\circ} .9,1991$, págs. 41-68. Griffin señala que existen dos modelos diferentes acerca de como están vinculados los deseos y los valores: por un lado, el modelo de la percepción, que otorga prioridad al valor (algo es deseado porque es valioso: juzgamos o reconocemos algo como valioso y, por consiguiente, sentimos un deseo por él): y por otro, el modelo del gusto, que otorga prioridad al deseo, al gusto, a la preferencia (algo es valioso porque es deseado: dado el tipo de criatura biológica y psicológica que somos, nuestros deseos van a fijarse en ciertos objetos, en virtud de lo cual éstos adquieren valor). En su opinión el modelo del gusto está muy -demasiado- difundido en las ciencias sociales, y sobre todo en la economía.

${ }^{50}$ Obra citada, capítulo 1, «A pluralist theory of value», págs. 1-16: concretamente, pág. 8. 
aquellos bienes que son meramente instrumentales y cuyo valor vendría dado por su precio relativo, y aquellos bienes que son fines en sí mismos y que gozarían de un valor intrínseco, que tienen en sí una dignidad?

No pretendo con estas preguntas y observaciones críticas minusvalorar la necesidad de aproximarnos al estudio del Derecho siendo conscientes de la relevancia económica de muchas cuestiones; ni tampoco rechazar las importantes contribuciones que el análisis económico ha realizado al desarrollo de las ciencias sociales y que los juristas debemos aprender a utilizar. Todo lo contrario. Sin embargo, sí es cierto que he pretendido poner de relieve algunas deficiencias y algunos peligros de las versiones más ortodoxas del análisis económico del Derecho, y alertar contra un peligro que ya Mill denunció en Bentham ${ }^{51}$, y que puede estar presente en algunos analistas económicos. Decía Mill que se hallaba Bentham tan orgulloso de su modelo basado en la noción de utilidad, que se aproximaba a todas las ideas como si fueran extrañas, como si fueran conceptos raros, nuevos; y si no conseguían pasar el examen de su modelo, las rechazaba como generalizaciones vagas y, por tanto, inútiles. Mill criticaba a Bentham por ignorar que en esas generalizaciones estaba contenida toda la sabiduría histórica de la especie humana; y por ello, aunque el modelo fuera incapaz de explicar esas ideas extrañas, era preciso permanecer atentos a ellas antes que despreciarlas. Mi temor es que una práctica acrítica y dogmática del análisis económico del Derecho pueda conducir a olvidar aquella parte de la sabiduría histórica de la humanidad que, con el paso del tiempo, ha ido sedimentándose en los diferentes saberes morales y jurídicos.

${ }^{51}$ Véase Calabresi, «Sobre los límites...», citada, pág. 228, de quien he tomado este argumento. 
$\Delta$

DOXA 15-16 (1994) 